\title{
Efficiency of use of metabolizable energy for body weight gain in pasture-based, nonlactating dairy cows
}

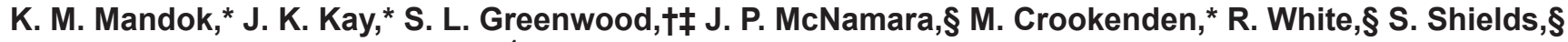 \\ G. R. Edwards, $\ddagger$ and J. R. Roche ${ }^{\star 1}$ \\ *DairyNZ, Private Bag 3221, Hamilton 3240, New Zealand \\ †Department of Animal Science, University of Vermont, Burlington 05405 \\ $\ddagger$ Faculties of Agriculture and Life Science, Lincoln University, Lincoln 7647, New Zealand \\ §Department of Animal Sciences, Washington State University, Pullman 99164
}

\section{ABSTRACT}

Four cohorts of nonlactating, pregnant dairy cows (n $=50,47,45$, and 42 ) were individually fed indoors to determine the amount of feed required for body weight (BW) gain from autumn pasture and commonly used supplementary feeds. These results were used to estimate the apparent efficiency with which metabolizable energy (ME) is used for BW gain (app_k $k_{\mathrm{g}}$ ). Control cows were offered autumn pasture to estimated maintenance requirements $\left(\sim 0.55 \mathrm{MJ}\right.$ of $\mathrm{ME} / \mathrm{kg}$ of $\left.\mathrm{BW}^{0.75}\right)$, with an additional $20 \mathrm{MJ}$ of $\mathrm{ME} / \mathrm{d}$ allocated for pregnancy and activity. All other cows received the same allowance of autumn pasture and an additional allowance (2.5 or 5.0 $\mathrm{kg}$ of dry matter/d) of autumn pasture (Past), spring pasture silage (Psil), maize silage (Msil), cracked maize grain (Mgr), or palm kernel expeller (PKE), resulting in a total of 11 treatments. Individual cow dry matter intake was determined daily; BW was recorded once per week for cohorts 1 and 2 , and 3 times per week for cohorts 3 and 4 . The ME contents of feeds were estimated from feed quality assays. Regression analyses were used on each feed to determine the ME requirement for $1 \mathrm{~kg}$ of BW gain. The app_k $\mathrm{k}_{\mathrm{g}}$ of Past and Msil was 0.34 and 0.47 , respectively; these estimates are in line with published literature. The app_ $\mathrm{k}_{\mathrm{g}}$ of Psil (0.50) was consistent with the published $\mathrm{k}_{\mathrm{g}}$ for spring pasture, from which the silage was made. Palm kernel expeller had the greatest app_k $k_{g}(0.61)$. The reasons for this cannot be deduced from the current study but may reflect the relatively high fat content of the feed and the high $\mathrm{k}_{\mathrm{g}}$ of fat. The app_ $\mathrm{k}_{\mathrm{g}}$ for Mgr was low (0.38) in comparison with the other supplementary feeds and, in particular, relative to its feed ME and published $\mathrm{k}_{\mathrm{g}}$ estimates. Although the reason for the low app_ $\mathrm{k}_{\mathrm{g}}$ cannot be deduced from the current data, the most plausible reason is the preferential use of propionate-derived glu-

Received April 10, 2013.

Accepted April 5, 2014.

${ }^{1}$ Corresponding author: john.roche@dairynz.co.nz cose for conceptus metabolism rather than BW gain, a factor not accounted for in previous experimental models that did not use late-gestation cows. In summary, the app_ $\mathrm{k}_{\mathrm{g}}$ for autumn pasture was low but consistent with historical growth rate trials in other ruminant species. In comparison, Msil, Psil, and PKE were used with a greater apparent efficiency $\left(\mathrm{app} \_\mathrm{k}_{\mathrm{g}}=0.47\right.$ to 0.61 ), but Mgr resulted in a relatively low rate of gain per MJ of ME (app_ $\left.\mathrm{k}_{\mathrm{g}}=0.38\right)$. These differences have implications for accurate feed budgeting on farm.

Key words: energy, efficiency of gain, pasture, grazing

\section{INTRODUCTION}

A cow's BCS is commonly used to evaluate its longterm nutritional status, with calving BCS identified by Roche et al. (2009a) as probably the most important measure of BCS in the intercalving profile because of its own effect on milk production and its association with BCS loss and the BCS nadir. Adequate nutrition and sufficient time to gain BCS during the nonlactating period are important in reaching these targets, particularly in grazing systems, where BCS gain during lactation is limited compared with that of cows fed TMR (Roche et al., 2007). It is important to know, therefore, the energy requirements for BCS and BW gain during this critical time. However, BCS is a subjective measure for which an objective automated procedure has not been commercialized. Instead, producers use automated daily $\mathrm{BW}$ measures to track the progress of cows to their BCS objectives. Although BW itself is not a reliable indicator of BCS (Roche et al., 2009a), frequent measurement of BW very likely reflects changes in BCS with relative accuracy, particularly when cows are not in early lactation, when BW loss is being masked by increases in DMI.

Net energy (NE) requirements for tissue gain are available from international feed standards (ARC, 1980; NRC, 2001; CSIRO, 2007), but consistent information on the efficiency with which ME is utilized for gain 
$\left(\mathbf{k}_{\mathrm{g}}\right)$ in late-gestation pregnant cows, and particularly under grazing conditions, is lacking. For example, fresh autumn temperate pasture has been assigned a $\mathrm{k}_{\mathrm{g}}$ of 0.34 (CSIRO, 2007); however, this figure is based on values obtained from growth studies involving sheep and steers (Blaxter et al., 1971; Grennan, 1999), arguably grazing much lower quality material than that offered to dairy cows (Roche et al., 2009b). MacRae et al. (1985) reported a $\mathrm{k}_{\mathrm{g}}$ of 0.43 for fresh autumn pasture in sheep, which is more consistent with the value for spring pasture in other publications (ARC, 1980; CSIRO, 2007) and the value for all pasture reported by the NRC (2001). The lack of dairy cow data and the inconsistency of assigning a $\mathrm{k}_{\mathrm{g}}$ to fresh pasture makes feed budgeting difficult in grazing systems, where cows are usually calved during spring, and autumn pasture is the primary feed used to gain body condition and BW before calving.

Grazing cows tend to be thinner in late lactation than cows fed a TMR (Roche et al. 2007), increasing the focus on BCS and BW gain during the dry period. To this end, other forages (e.g., maize silage and pasture silage) and fermentable fiber-based concentrates (e.g., palm kernel expeller) are often offered as supplements to pasture during the nonlactating period to accelerate BCS and BW gain. Although $\mathrm{k}_{\mathrm{g}}$ values are reported for some of these feeds (NRC, 2001), they have not been investigated in conjunction with fresh pasture nor, in most instances, in late-gestation nonlactating dairy cows. Because different feed types can have a different $k_{g}$ (NRC, 2001), the objective of this experiment was to determine the BW gain associated with autumn pasture and supplementary feeds that are commonly used in temperate grazing systems, and to use these data to estimate the $\mathrm{k}_{\mathrm{g}}$ (i.e., apparent $\mathrm{k}_{\mathrm{g}}$ : $\mathbf{a p p} \_\mathbf{k}_{\mathrm{g}}$ ) of these feeds; these estimates will then be compared with published values.

\section{MATERIALS AND METHODS}

All procedures were approved by the Ruakura Animal Ethics Committee (No. 12238).

\section{Treatments}

Over 2 yr, 184 multiparous, pregnant, and nonlactating Holstein-Friesian and Holstein-Friesian $\times$ Jersey cross dairy cows were offered fresh pasture in a Calan Gate (American Calan, Northwood, NH) freestall facility (DairyNZ Lye Farm, Hamilton, New Zealand) for $38 \pm 2 \mathrm{~d}$ (mean $\pm \mathrm{SD})$. Because of a limited number of feeding stations, cows were divided into 4 cohorts $(\mathrm{n}=$ $50,47,45,42)$. Cows were randomly allocated to treatment, ensuring that cow BW, age, and day of gesta- tion were balanced across treatments. Estimated mean $( \pm \mathrm{SD})$ day of gestation, BW, and age at the start of the experiment were $189( \pm 16) \mathrm{d}, 521( \pm 58) \mathrm{kg}$, and 6 $( \pm 2)$ yr, respectively. To avoid any confounding effects associated with growth in stature, only cows that were in their third or greater lactation were enrolled. All cows had been previously trained to the feeding facility.

Animals in the control treatment $(\mathrm{n}=18)$ were offered fresh autumn pasture to provide sufficient ME for estimated maintenance requirements (0.55 MJ of ME/ $\mathrm{kg}$ of $\mathrm{BW}^{0.75}$; Holmes et al., 2002) and an additional allowance for limited activity and pregnancy $(\sim 20 \mathrm{MJ}$ of ME; NRC, 2001; Nicol and Brookes, 2007). Cows in all other treatments were fed the control diet plus an additional 2.5 (low) or 5.0 (high) $\mathrm{kg}$ of DM of 1 of 5 feeds: pasture (Past), pasture silage (Psil), maize silage (Msil), maize grain (Mgr), and palm kernel expeller (PKE). This equated to the Past, Psil, Msil, Mgr, and PKE treatments having 16 and 17, 17 and 17, 17 and 17, 16 and 17, and 16 and 16 cows in the low and high feed allocation treatments, respectively.

\section{Feed Management}

Supplementary feeds were offered once per day at approximately $0800 \mathrm{~h}$ to best mimic normal farm practice, and freshly cut autumn pasture was offered after the cows finished their supplement allocation. The supplement allocation was deemed to be finished once cows showed no further interest in the feed offered and left their feeding station. Supplementary feeds were offered in a separate container and were not removed when pasture was offered. This enabled cows to continue eating their supplement throughout the day as would be the case in farm practice. Control and Past cows received their complete allocation at $0800 \mathrm{~h}$. Cows were kept indoors for approximately $7 \mathrm{~h}$, after which they were released onto an empty lot (bare paddock) with no feed available until the next morning. Water was available at all times.

Pasture offered and refused were recorded daily for each cow, and representative pooled samples of pasture offered and refused and supplementary feed offered were obtained daily and dried in triplicate at $95^{\circ} \mathrm{C}$ for $48 \mathrm{~h}$ to determine DM content (\%) and calculate DMI. Representative samples of supplementary feeds refused were collected from each cow and dried at $95^{\circ} \mathrm{C}$ for 48 $\mathrm{h}$. If a refusal sample was $\leq 300 \mathrm{~g}$, the whole sample was dried. Additional feed samples $(2 \times 150 \mathrm{~g})$ were collected daily, dried at $60^{\circ} \mathrm{C}$ for $72 \mathrm{~h}$, ground to pass through a 2.0-mm sieve (Christy Lab Mill, Suffolk, UK), pooled weekly, and analyzed for nutrient composition and ME determination by wet chemistry (Ankom Technology Method 3, DairyOne, Ithaca, NY; NRC, 
Table 1. Composition ${ }^{1}$ (means with SD in parentheses) of feeds evaluated (\% of DM unless otherwise stated)

\begin{tabular}{lccccc}
\hline & \multicolumn{3}{c}{ Treatment } \\
\cline { 2 - 5 } & $\begin{array}{c}\text { Maize } \\
\text { grain }\end{array}$ & $\begin{array}{c}\text { Maize } \\
\text { silage }\end{array}$ & $\begin{array}{c}\text { Autumn } \\
\text { pasture }\end{array}$ & $\begin{array}{c}\text { Pasture } \\
\text { silage }\end{array}$ & $\begin{array}{c}\text { Palm kernel } \\
\text { expeller }\end{array}$ \\
\hline DM (\% of fresh matter) & 85.3 & 39.5 & 15.0 & 28.5 & 92.9 \\
& $(7.08)$ & $(5.51)$ & $(3.63)$ & $(3.86)$ & $(7.94)$ \\
ME (MJ/kg of DM) & 14.1 & 10.3 & 12.4 & 11.6 & 11.0 \\
CP & $(0.11)$ & $(0.42)$ & $(0.64)$ & $(0.56)$ & $(0.66)$ \\
& 8.5 & 7.5 & 21.8 & 17.6 & 18.6 \\
Crude fat & $(0.62)$ & $(0.36)$ & $(1.68)$ & $(1.85)$ & $(0.88)$ \\
& 3.7 & 3.1 & 4.1 & 4.1 & 9.6 \\
NDF & $(0.39)$ & $(0.52)$ & $(0.92)$ & $(2.33)$ & $(0.79)$ \\
& 9.4 & 41.4 & 47.4 & 53.6 & 60.9 \\
NFC & $(0.92)$ & $(2.95)$ & $(5.21)$ & $(2.83)$ & $(3.71)$ \\
Starch & 77.9 & 44.0 & 22.4 & 15.9 & 15.8 \\
& $(1.09)$ & $(3.48)$ & $(6.57)$ & $(3.28)$ & $(3.41)$ \\
24-h in vitro true digestibility & 71.7 & 38.0 & 1.1 & 1.0 & 0.4 \\
& $(2.03)$ & $(2.86)$ & $(1.07)$ & $(0.72)$ & $(0.27)$ \\
24-h NDF digestibility (\% of NDF) & 95.6 & 73.6 & 82.1 & 76.9 & 52.4 \\
& $(1.08)$ & $(2.82)$ & $(3.81)$ & $(3.91)$ & $(3.01)$ \\
& $(10.1$ & 36.0 & 61.8 & 56.7 & 21.5 \\
& $(4.91)$ & $(8.19)$ & $(7.83)$ & $(6.54)$ \\
\hline
\end{tabular}

${ }^{1}$ Analyzed for nutrient composition by wet chemistry (Ankom Technology Method 3; DairyOne, Ithaca, NY). The method for estimating ME from forages based on ADF is not appropriate for temperate forages (CSIRO, $2007)$; therefore, the $\mathrm{ME}(\mathrm{MJ} / \mathrm{kg}$ of $\mathrm{DM})$ for pasture and pasture silage was calculated from in vitro true digestibility (after $24 \mathrm{~h}$ of incubation, Ankom Technology Method 3, DairyOne) as DM digestibility $\times 0.172-1.707$ (CSIRO, 2007). Twenty samples were analyzed for each feed.

2001; Table 1). The method for estimating ME from forages based on ADF is not appropriate for temperate forages (CSIRO, 2007); therefore, the $\mathrm{ME}(\mathrm{MJ} / \mathrm{kg}$ of DM) for Past and Psil was calculated from in vitro true digestibility (after $24 \mathrm{~h}$ of incubation, Ankom Technology Method 3, DairyOne) as DM digestibility $\times 0.172$ - 1.707 (CSIRO, 2007). Twenty samples were analyzed for each feed.

Permanent pastures (2-7 yr old) growing on a shallow peat soil were mechanically harvested daily; cutting height was approximately $50 \mathrm{~mm}$. The harvested pasture was typical of that offered to nonlactating cows in grazing systems (i.e., pasture mass of 3,000 to $4,000 \mathrm{~kg}$ of DM/ha). It comprised perennial ryegrass (Lolium perenne L.; varieties: Bronsyn AR1 and AR37; 82\% DM), white clover (Trifolium repens; $5 \%$ DM), dead herbage (7\% DM), and weed species (5\% DM: mainly Plantago major, Ranunculus repens, and Crepis capillaris). Pasture silage was made from spring pastures botanically similar to the previous description. The pasture was precision chopped and a 24-h wilt inoculant (Pioneer 1127, Genetic Technologies, Auckland, New Zealand) was added. The maize silage (hybrid Pioneer 0791) was finely chopped and kernel processed to crack the grains. An inoculant (Pioneer 11C33) was added to the silage.

\section{$B C S$ and $B W$}

Cows were weighed on 2 consecutive days and BCS was determined once $3 \mathrm{~d}$ before beginning the experi- ment and once $3 \mathrm{~d}$ after completing the experiment (to allow equilibrium of gastrointestinal contents). During the experiment, BCS for each cow was recorded once per week by one experienced recorder; the recorder was "blinded" to his previous assessment result. Body weight was recorded once per week in cohorts 1 and 2, and 3 times per week in cohorts 3 and 4 . Body weight and BCS measurements were recorded at approximately $0730 \mathrm{~h}$ (before feeding). Body condition score was assessed on a 10-point scale, where 1 is emaciated and 10 is obese (Roche et al., 2004). The scores can be converted to the 5 -point scale using the regression equation generated by Roche et al. (2004; 5 -point BCS $=1.5+0.32 \times 10$-point BCS).

\section{Blood Sampling and Analysis}

On $1 \mathrm{~d}$ each week and before feeding, blood was collected by coccygeal venipuncture into $10-\mathrm{mL}$ heparinized (NaHep), evacuated tubes (Vacutainer, Becton Dickinson, Franklin Lakes, NJ). Tubes were placed immediately into ice and centrifuged within $60 \mathrm{~min}$ at $3,000 \times g$ for $12 \mathrm{~min}$ at $4^{\circ} \mathrm{C}$. Following centrifugation, plasma was aspirated and aliquots stored at $-20^{\circ} \mathrm{C}$ until analysis.

Plasma samples were analyzed at Gribbles Veterinary Pathology Ltd. (Hamilton, New Zealand) for BHBA, NEFA, aspartate aminotransferase (AST), glutamate dehydrogenase (GDH), and glucose. Metabolite assays were performed using colorimetric techniques at 
$37^{\circ} \mathrm{C}$ with a Hitachi Modular P800 analyzer (Roche Diagnostics, Indianapolis, IN). Roche reagent kits were used to measure plasma concentrations of AST (IU/L; conversion of $\alpha$-oxoglutarate and L-aspartate to L-glutamate and oxaloacetate), GDH (IU/L; reduction of $\alpha$-oxoglutarate), glucose (mmol/L; glucose oxidase method) and BHBA (mmol/L; reduction of NAD to $\mathrm{NADH}$ during oxidation of D-3-hydroxybutyrate to acetoacetate). Plasma NEFA concentrations (mmol/L) were measured using Wako Chemicals (Osaka, Japan) kit NEFA HR2, which measures oxidative condensation of 3-methyl- $N$-ethyl- $N$ - $\beta$ hydroxyethyl aniline with 4-aminoantipyrine.

\section{Statistical Analyses and Calculations}

Statistical analyses were conducted in GenStat (VSN International, 2011).

Analysis of Treatment Effects on DMI, BW Gain, and BCS Gain. Body weight gain per day was calculated for each cow from all her BW measurements during the experimental period using regression analysis, with BW as the dependent variable and day from start of the experiment as the independent variable. The slope of this line fitted for each cow is her average daily BW gain. Daily BCS gain was calculated in the same way. This method of estimating BCS versus BW gain uses all of the measurements collected and gives a better estimate of gain than that obtained using the difference of initial versus final measurement. No gain data were omitted due to poor fit, but some estimates of gain were negative. Daily DMI for each cow was calculated as the average of her daily DMI during the experimental period. Each of these was then analyzed for treatment effects using mixed models, including cohort, supplementation (control vs. supplement), supplement type, amount, and the interaction of supplement type and amount as fixed effects, and cow as the random effect.

Calculation and Analysis of app_k $k_{g}$ Combining DMI and BW Gain Data. Energy (MJ of ME) intake and $\mathrm{BW}$ gain were combined to calculate the app_ $\mathrm{k}_{\mathrm{g}}$ for each supplement type, taking into account the BW gain of each cow relative to her additional intake of energy. Because of possible substitution effects, the additional DMI for each cow was calculated by subtracting the mean control intake for the cohort from the intake of each cow in the cohort.

The app_ $\mathrm{k}_{\mathrm{g}}$ was calculated by initially using regression analysis for each cohort and each supplement type to estimate the slope of the line fitted to BW gain for each cow as the dependent variable, and additional MJ of ME intake as the independent variable. The model used had a common intercept (representing the BW change for no additional intake) for the 5 supplement types but different slopes for each supplement. This was repeated for each cohort, giving 4 estimates of the slope for each supplement type (1 from each cohort); the model used was

$$
y_{i j k}=a_{i}+b_{i j} \times\left(\text { intake }_{i j k}-c_{i}\right)+e_{i j k},
$$

where $i$ is cohort (i.e., 1-4), $j$ is supplement type, and $k$ is cow; $y_{i j k}$ is the BW gain of $\operatorname{cow}_{i j k}$ on supplement $j$ of cohort $i, a_{i}$ is the intercept for cohort $i$ (i.e., the BW change, if not supplemented), $b_{i j}$ is the slope for supplement $j$ in cohort $i$, intake $_{i j k}$ is ME intake (MJ) for $\mathrm{cow}_{i j k}$, $c_{i}$ is the ME intake (MJ) for the control cows in cohort $i$, and $e_{i j k}$ is the error term.

The 20 slopes $\left(b_{i j}\right)$ were then analyzed in a weighted analysis using linear models that included cohort and supplement type as fixed effects and the square reciprocal of the standard errors of the fitted sloped as weights.

Apparent efficiency of use of energy for BW gain (app_ $k_{g}$ ) was calculated as $25 \times$ slope, because $25 \mathrm{MJ}$ of $\mathrm{NE}$ is the average energy contained in $1 \mathrm{~kg}$ of $\mathrm{BW}$ (Holmes et al., 2002). The reciprocal of the slope was also calculated to provide an estimate of the MJ of ME of supplement needed for $1 \mathrm{~kg}$ of BW gain.

Analysis of Blood Data. For each blood metabolite, the average of the 5 -wk measurement period was calculated for each cow and these averages were then analyzed using mixed models including covariate, cohort, supplementation (control vs. supplement), supplement type, supplement amount, and the interaction between supplement type and amount as fixed effects and cow as the random effect. A $\log _{10}$ transformation was used for AST, GDH, and NEFA because of heterogeneity of the variance (detected by a residual plot of the residuals from the analysis).

\section{RESULTS}

Nutrient composition, $\mathrm{ME}$, and in vitro DM and NDF digestibility of experimental feeds are presented in Table 1. On average, control cows consumed $7.5 \mathrm{~kg}$ of $\mathrm{DM} /$ cow per day, with the total DMI for the other treatments ranging from 9.4 to 10.0 and from 10.3 to $11.9 \mathrm{~kg} \mathrm{DM} /$ cow per day for the low and high allocations, respectively (Table 2). Daily average ME intake was $94 \mathrm{MJ} / \mathrm{d}$ for control cows and ranged from 114 to $127 \mathrm{MJ} / \mathrm{d}$ and 125 to $157 \mathrm{MJ} / \mathrm{d}$ for the supplemented groups in the low and high allocation treatments, respectively (Table 2). We detected interactions between supplement type and supplement amount for DMI $(P<$ $0.05)$ and ME intake $(P<0.001$; Table 2$)$.

Body weight gain per day was greater $(P<0.001)$ in cows fed supplements compared with control cows and 
greater $(P<0.001)$ in high compared with low feeding allocations, irrespective of feed type. Body weight gain was also affected $(P<0.001)$ by feed type, with cows on the Past treatment gaining less $\mathrm{BW}$ than cows on the other treatments (Table 2). This effect also tended to be significant for BCS gain $(P=0.10)$. On average, $66,53,74,50$, and $41 \mathrm{MJ}$ of ME were consumed per 1 $\mathrm{kg}$ of BW gain for cows on Mgr, Msil, Past, Psil, and PKE, respectively.

Average plasma concentrations of the metabolic indicators of energy status measured (i.e., AST, GDH, BHBA, NEFA, and glucose) are reported in Table 3. Concentrations of AST and GDH were greater $(P<$ $0.01)$ in control cows than in cows on the Mgr and PKE treatments, and GDH concentrations were greater $(P<$ $0.05)$ in control than Psil cows. Plasma concentrations of BHBA were lower $(P<0.001)$ in control cows than in cows on Mgr and PKE but not those on Past and Psil; BHBA concentrations in Mgr and PKE cows were greater $(P<0.001)$ than for cows on Past and Psil but did not differ from each other. Plasma NEFA concentrations were greater $(P<0.001)$ in cows in the control group than in any of the supplemented treatments, were lower $(P<0.001)$ in Mgr cows than in cows in any other treatment, and lower in high compared with low allocation cows. Plasma glucose concentrations from control cows were lower $(P<0.01)$ than those in cows in Mgr, PKE, and Psil treatments, but were not different from cows consuming Msil and Past. Glucose concentration was greater in PKE cows $(P<0.05)$ than in Msil and Past cows but not different from cows on Mgr and Psil.

\section{DISCUSSION}

The presented results indicate that different amounts of supplementary feeds are required to gain $1 \mathrm{~kg}$ of BW in nonlactating, late-gestation, pasture-based dairy cows. Body weight increased with feeding level; this was supported by blood metabolite data, with the lower NEFA concentrations with increasing ME intake indicating a greater uptake of NEFA to adipose tissue relative to NEFA release (i.e., increased lipogenesis), greater plasma glucose concentrations, and lower plasma AST and GDH concentrations in supplemented cows. Reported interactions between supplement type and supplement amount were the result of differences in DMI and ME intake between supplement types, as the experimental protocol offered the same DM amount of each supplementary feed and differences were observed in both feed energy density and the amount of feed consumed. For example, the difference in DMI and ME intake between cows on the high and low supplement amount was greater for Mgr than for Past and PKE (Table 2).

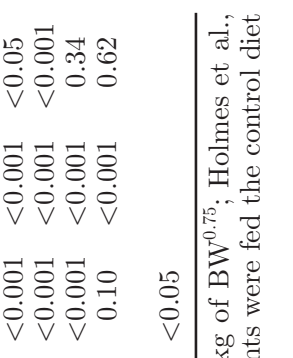

$\overrightarrow{8} \overrightarrow{8} \overrightarrow{8} \overrightarrow{8}$ $\dot{\vec{V}} \dot{\vec{V}} \dot{\vec{V}} \dot{\vec{V}}$ 至 ๑. bo ง 它

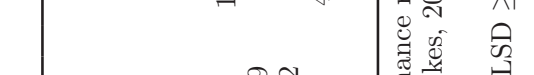

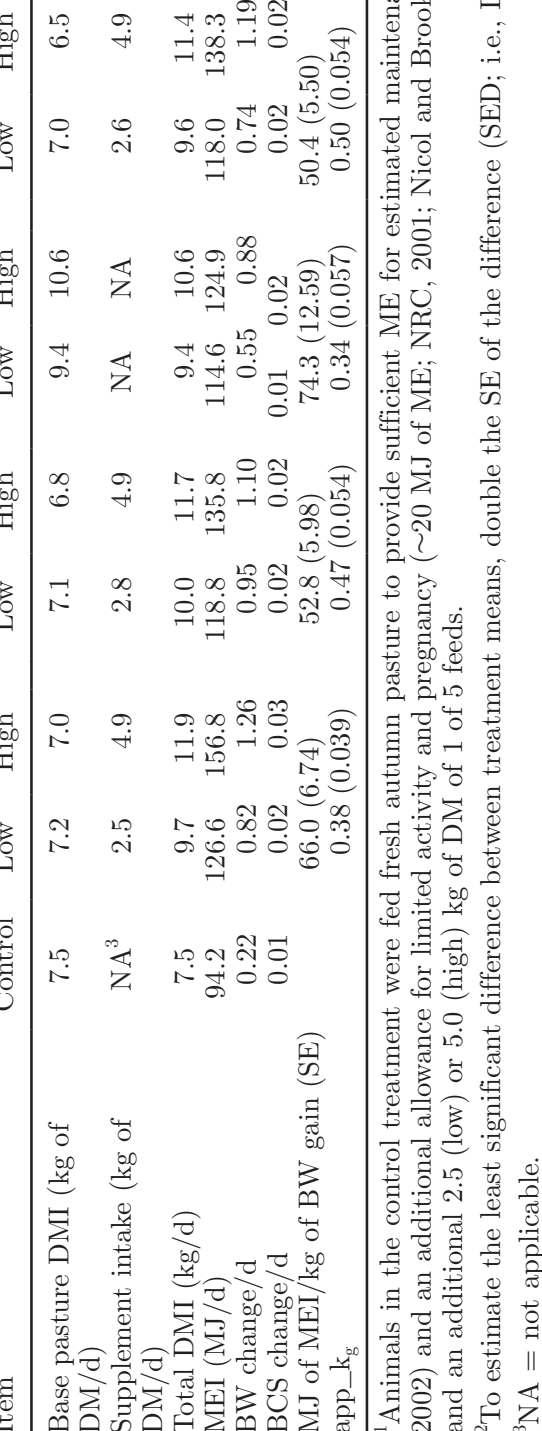


A logical extension of the DMI, BW gain, and feed $\mathrm{ME} / \mathrm{kg}$ of DM data are an estimation of the efficiency with which ME is used for BW gain (apparent $\mathrm{k}_{\mathrm{g}}$ : app_ $\mathrm{k}_{\mathrm{g}}$ ). The differences in the DMI and ME intake of different feeds for each $1 \mathrm{~kg}$ of $\mathrm{BW}$ gain are equivalent to app_k $\mathrm{k}_{\mathrm{g}}$ of $0.38,0.47,0.34,0.50$, and 0.61 for Mgr, Msil, Past, Psil, and PKE, respectively (Table 2). In short, in the chosen experimental model (i.e., nonlactating, late-gestation dairy cow), Past and Mgr were used with low apparent efficiency, PKE with relatively high apparent efficiency, and Msil and Psil with intermediate apparent efficiency.

The current experimental design has 3 particularly novel features: first, there is a paucity of information on the use of pasture for BW gain in dairy cows; second, limited, if any, data are available on the efficiency with which the feeds evaluated are used for BW gain when pasture is the base diet; and third, the experimental model of a late-gestation cow offers a unique physiological perspective to the area of BW gain, with most growth studies undertaken in nonpregnant animals, from which extrapolation to the late-gestation dairy cow may not be appropriate because conceptus metabolism adds to the nutrient sinks and to the complexity of nutrient partitioning. A deficiency of the study design, admittedly, is the assumption that the changes in BW predict a linear change in energy retention, as it was not possible to measure body compositional changes; this will be discussed further in relation to the data from cows supplemented with maize grain. An additional limitation is the use of laboratory derived and calculated ME values, which, at best, are only close estimates of actual feed ME. Nonetheless, they are the values supplied by laboratories to producers and their advisers. In addition, the values are very close to what would be expected from detailed studies of these feeds and, so, at worst, would affect the estimated $\mathrm{k}_{\mathrm{g}}$ by only a few percent. In the discussion of this research, we are not suggesting that such small differences are real. Nevertheless, these limitations must be acknowledged and, in so doing, throughout the document we refer to "app_k $k_{\mathrm{g}}$ " or "apparent efficiency." Future research should aim to extend the knowledge presented here by measuring changes in body composition or accurate animal-derived ME estimates of the feeds compared to help better understand the effect of feed type in the late-gestation dairy cow model.

\section{Pasture, Pasture Silage, and Maize Silage}

The apparent efficiency with which ME from Past, Psil, and Msil was used for BW gain is consistent with previous publications in ruminant species (NRC, 2001; CSIRO, 2007). In the present experiment, cows con- 
suming autumn pasture gained the least amount of BW per kilogram of DMI and per megajoule of ME, indicating a low app_ $k_{g}$ for pasture compared with Msil, Psil, and PKE. Values are consistent with those reported by CSIRO $\left(2007 ; \mathrm{k}_{\mathrm{g}}=0.34\right)$, as well as BW gain studies in sheep and cattle fed autumn pasture and spring pasture at similar digestibilities (Clarke, 1959; Blaxter et al., 1971). These values are less than the $\mathrm{k}_{\mathrm{g}}$ value $(0.43)$ outlined by the NRC (2001), but this may be due to a failure to recognize the effect of season on the $\mathrm{k}_{\mathrm{g}}$ value for cool-season pastures. CSIRO (2007) recommend a $\mathrm{k}_{\mathrm{g}}$ similar to that reported by the NRC (2001), but only for spring pasture (0.42), acknowledging an effect of season on the conversion of DM digestibility to ME.

The reason for the low app_ $\mathrm{k}_{\mathrm{g}}$ for autumn pasture is not known, but differences in voluntary DMI (Clarke, 1959) or soluble carbohydrate content (Corbett et al., 1966) or differences in the amounts of absorbed glycogenic AA (MacRae et al., 1985) have been proposed. MacRae et al. (1985) infused casein into the abomasum of sheep consuming autumn pasture and reported an increase in the efficiency of body fat accretion; they hypothesized that an extra supply of AA could provide additional NADPH and glycerol phosphate for the conversion of acetate into FA, thereby improving the efficiency of use of energy for lipogenesis. The blood metabolites measured here do not offer an explanation for the low app_k $\mathrm{k}_{\mathrm{g}}$ of autumn pasture, although the greater plasma NEFA concentrations are consistent with a less positive energy balance in the Past group.

Collectively, the results indicate that the apparent efficiency with which ME from autumn pasture is used for BW gain in nonlactating pregnant dairy cows is low and similar to reported efficiency values in sheep and beef cattle. Although spring pasture was not evaluated in this study, the higher app_k $k_{g}$ for silage made from spring pasture and the reported difference in $\mathrm{k}_{\mathrm{g}}$ between spring and autumn pasture (CSIRO, 2007) indicate that the season of harvest of cool-season pastures must be considered when predicting BW gain. From a farm management standpoint, cows that are fed autumn pasture need more feed $\mathrm{ME}$ and more time to gain $\mathrm{BW}$ and BCS than cows on the other feeds evaluated.

The apparent efficiency with which ME was used for BW gain was similar in Msil and Psil, which were both more efficient for BW gain than autumn pasture. In the current study, Msil had an app_k $\mathrm{k}_{\mathrm{g}}$ of 0.47 , which is similar to the 0.42 to 0.44 reported by the NRC (2001) and CSIRO (2007). Apparent efficiency values for Psil $\left(\right.$ app_ $\left.k_{g}=0.50\right)$ were also within the range of values reported by the NRC (2001) and CSIRO (2007) for spring pasture, from which the silage was made, as well as with the reportedly greater $\mathrm{k}_{\mathrm{g}}$ of pasture in spring compared with autumn (Blaxter et al., 1971; MacRae et al., 1985). Consistent with the relatively high app_ $k_{g}$ for pasture silage, Moorby et al. (2008) studied differences in the BW gain of late-gestation dairy cows and associated calf birth weights, when cows were fed either pasture silage or red clover silage. That study revealed a greater BW gain in cows on pasture silage, whereas cows on clover silage gave birth to heavier calves. This may be due to differences in the products of rumen fermentation and associated differences in the partitioning of nutrients to physiological processes; for example, by promoting the production of acetate in the rumen, pasture silage might favor the use of dietary end products for fat synthesis rather than conceptus metabolism (Battaglia and Meschia, 1978), thereby promoting maternal BW gain. This hypothesis is consistent with the reasonable gain of maternal $\mathrm{BW}$ in cows on pasture silage in this experiment.

\section{Palm Kernel Expeller}

Cows fed PKE required the least amount of $\mathrm{ME} / \mathrm{kg}$ of BW gain (41 MJ of ME), resulting in an app_k $k_{g}$ of 0.61 (Table 2). Even though PKE is not a feed ingredient that has been extensively investigated, the available data support a positive effect of PKE on BW gain when it is fed as the main dietary component (Mak et al., 1986) or in conjunction with tropical pasture (Galgal and Komolong, 2000; Zahari and Alimon, 2004). For example, Umunna et al. (1980) investigated PKE as an alternative to other common feedstuffs of similar energy density for Nigerian beef production (e.g., groundnut cake or cottonseed cake) and concluded that cattle fed PKE needed less feed to gain BW than those offered similar comparable feeds (i.e., feed conversion efficiency was better for the PKE supplemented group). Zahari and Alimon (2004) reported improved digestibility of PKE when fed in addition to pasture and proposed that this was due to reduced passage rates of PKE in the rumen and gastrointestinal tract and a resultant greater ruminal retention time. In many of these studies, PKE was fed as a high percentage of the diet or in combination with poor quality tropical pastures and was not fed as a supplement to pregnant dairy cows. It is difficult, therefore, to conclude too much from these studies regarding the $\mathrm{k}_{\mathrm{g}}$ of $\mathrm{PKE}$ as it pertains to the experimental model tested here.

Although little research is available on the effects of PKE on BW gain, plausible reasons can explain the high efficiency: the high fat content of PKE $(9.6 \%$; Table 1), the increased availability of acetate from rumen fermentation of fiber in combination with the animal model used in this experiment (i.e., late-gestation dairy cow), and improved rumen function or additive 
associative effects from feeding PKE in combination with pasture.

As the acetate and medium- to long-chain FA derived from PKE digestion are not used to any appreciable extent for conceptus metabolism (Battaglia and Meschia, 1978), the energy available to the cow from PKE digestion is more likely to be partitioned toward anabolic processes. This is certainly a plausible explanation for a greater app_ $k_{g}$ in PKE than in other feeds.

In addition to the energy density of fat and the preferential partitioning of energy from FA toward anabolic processes in late-gestation cows, however, the possibility of a positive effect of PKE on BW gain through a positive effect on rumen function should be considered. Abdullah and Hutagalung (1988) reported a partial rumen-defaunating effect of PKE, and Bird and Leng (1978) reported increased amounts of isoacids in the rumen fluid of ruminants fed PKE. Both of these factors would be expected to improve microbial protein yield and cellulose digestion (Russell and Sniffen, 1984), thereby increasing the ME of the total diet and, possibly, microbial protein supply to the small intestine. Both of these could improve production from PKE beyond the additive effect of nutrients consumed. For example, MacRae et al. (1985) reported a 27\% increase in the $\mathrm{k}_{\mathrm{g}}$ of cows consuming fresh autumn pasture when casein was infused abomasally, thereby suggesting an AA limitation to BW gain in ruminants grazing autumn pasture. It is possible, therefore, that the high app_ $\mathrm{k}_{\mathrm{g}}$ for PKE reported here is a result of positive associative effects on rumen function from combining PKE with pasture, rather than an effect of PKE per se. This has potential implications for milk production and BW gain of other ruminant species and requires further investigation.

Irrespective of the reason for the greater $\mathrm{BW}$ gain per kilogram of feed DM or ME consumed, the data presented indicate that PKE is used efficiently for BW gain by late-gestation, nonlactating dairy cows. However, DMI of PKE was low relative to that of the other supplementary feeds. This was most likely due to a palatability effect of PKE, with cows in the high PKE treatment not eating all of their allocation. This factor must be considered in any feed plan.

\section{Maize Grain}

Body weight gain was greatest for cows in the Mgr treatment, a fact consistent with the lowest circulating NEFA concentrations $(P<0.001)$. This was because cows in this treatment consumed the most $\mathrm{ME}(\mathrm{MJ} / \mathrm{d})$. However, the BW gain per megajoule of ME intake was numerically lower than in all other feeds (with the exception of pasture), resulting in a low app_ $\mathrm{k}_{\mathrm{g}}$ for $\mathrm{Mgr}$ compared with the $\mathrm{k}_{\mathrm{g}}$ stated in NRC $(2001 ; 0.47)$ and CSIRO (2007). The reason for this low app_ $\mathrm{k}_{\mathrm{g}}$ is not clear, but we hypothesize that it is for 1 of 2 possible reasons: (1) differences in the products of digestion influencing the partitioning of energy, or (2) differences in the composition of the BW gain.

The high starch content of Mgr will have resulted in a greater production of ruminal propionate relative to acetate (Bauman et al., 1971). Because propionate functions as the main precursor for gluconeogenesis in the ruminant liver, glucose production should be greater in Mgr-fed cows. Late-gestation insulin resistance through decreased glucose transporter type- 4 expression would be expected to reduce glucose uptake by maternal peripheral tissues (muscle and adipose; Bell and Bauman, 1997), whereas the coincidental increased expression of glucose transporter type-3 (Das et al., 2000) would facilitate uptake of glucose by the conceptus. These physiological changes could increase partitioning of $\mathrm{ME}$ from Mgr to conceptus metabolism rather than BW gain, and may explain the lower app_ $\mathrm{k}_{\mathrm{g}}$ of $\mathrm{Mgr}$ in these late-gestation dairy cows. Differences in BW gain and calf birth weight reported by Moorby et al. (2008) in cows fed either pasture silage or red clover silage supports this hypothesis, with greater BW gain on pasture silage and greater calf birth weight on the red clover silage treatment. The effect of treatment in the current study cannot be used to test this hypothesis, because the time on feed treatment and number of cows per treatment does not provide the statistical power to detect differences in calf birth weight if they occurred.

An alternative hypothesis is that the low app_ $k_{g}$ for Mgr is a result of our assumption that BW gain reflects a similar retention in energy, irrespective of feed type, and that there were, in fact, differences in the composition of tissue gained on the different treatments that were not accounted for in the current experiment. In the present study, each $1 \mathrm{~kg}$ of $\mathrm{BW}$ gain was assumed to contain 25 MJ of NE (Holmes et al., 2002). However, as the energy and water content of fat and protein differ (CSIRO, 2007), the composition of the BW gained can affect the app_ $k_{g}$ assigned to the feed. Propionate from starch digestion (from Mgr) and the associated increase in insulin secretion (Bell and Bauman, 1997) may have resulted in a greater proportion of adipose tissue in the BW gain relative to protein. If this hypothesis is correct, the app_ $\mathrm{k}_{\mathrm{g}}$ assigned to Mgr in the current experiment would underestimate the efficiency with which ME was used for BW gain. However, late gestational insulin resistance is likely to limit insulin-induced lipogenesis. Furthermore, Muir et al. (1998) reported no distinguishable differences in specific marbling characteristics in steers finished on either an Mgr-based diet or on high-quality spring 
pasture, implying that a difference in composition of gain from these feeds is unlikely. Even though fat depth and marbling increased with increasing BW, they could not attribute any treatment effect to feed type. Although body composition was not measured in the present experiment, the energy partitioning hypothesis is likely the more plausible based on previous experimental evidence. Results indicate the need to consider the physiological state of the animal in assigning a $\mathrm{k}_{\mathrm{g}}$ value to feed ingredients, especially if the animal is in late gestation and the feed is propionigenic.

\section{CONCLUSIONS}

The app_ $\mathrm{k}_{\mathrm{g}}$ for autumn pasture was low (0.34) but consistent with historical growth rate studies in other species. The app_ $k_{g}$ for maize silage and pasture silage fed as a supplement to autumn pasture were 0.47 and 0.50 , suggesting good BW gains from these feeds in the nonlactating period. Surprisingly, the app_ $k_{g}$ of maize grain in this study was relatively low (0.38), whereas that for PKE was high (0.61). We hypothesized that these unexpected differences in nonlactating animals relate to the stage of pregnancy and the preferential use of specific nutrients for conceptus metabolism in mammals, although positive associative effects of PKE and pasture cannot be ruled out. Although the technique used here has its limitations, the results for maize silage, pasture silage, and fresh pasture are all consistent with values in the literature. Although the app_kg for PKE was high and that for maize grain low, there are plausible reasons for why this occurred. Overall, the results indicate that this technique can be used to assess the apparent efficiency with which different sources of ME are used for BW gain.

\section{ACKNOWLEDGMENTS}

The authors thank DairyNZ (Hamilton, New Zealand) technical and farm staff for their help during feeding and sample collection. DairyNZ Inc. (Project No. AN803 and AN1010) and the Ministry of Primary Industries New Zealand, through the Sustainable Farming Fund (Project No. 08/012), provided financial support. We gratefully acknowledge the assistance of Barbara Dow (Dairy NZ) with statistical analysis and interpretation.

\section{REFERENCES}

Abdullah, N., and R. I. Hutagalung. 1988. Rumen fermentation, urease activity and performance of cattle given palm kernel cakebased diet. Anim. Feed Sci. Technol. 20:79-86.

ARC. 1980. The Nutrient Requirements of Ruminant Livestock. M. Freer, ed. CAB International, Wallingford, UK.
Battaglia, F. C., and G. Meschia. 1978. Principal substrates of fetal metabolism. Physiol. Rev. 58:499-527.

Bauman, D. E., C. L. Davis, and H. F. Bucholtz. 1971. Propionate production in the rumen of cows fed either a control or high-grain, low-fiber diet. J. Dairy Sci. 54:1282-1287.

Bell, A. W., and D. E. Bauman. 1997. Adaptations of glucose metabolism during pregnancy and lactation. J. Mammary Gland Biol. Neoplasia 2:265-278.

Bird, S. H., and R. A. Leng. 1978. The effects of defaunation of the rumen on the growth of cattle on low-protein high-energy diets. Br. J. Nutr. 40:163-167.

Blaxter, K. L., F. W. Wainman, P. J. S. Dewey, J. Davidson, H. Denerley, and J. B. Gunn. 1971. The effects of nitrogenous fertilizer on the nutritive value of artificially dried grass. J. Agric. Sci. 76:307-319.

Clarke, E. A. 1959. A Summary of Intake Studies with Hoggets. Pages 91-98 in Proc. N. Z. Soc. Anim. Prod. Vol. 19. N. Z. Soc. Anim. Prod. Ruakura Agricultural Station, Hamilton, New Zealand.

Corbett, J. L., J. P. Langlands, I. McDonald, and J. D. Pullar. 1966. Comparison by direct animal calorimetry of the net energy values of an early and a late season growth of herbage. Anim. Prod. $8: 13-27$.

CSIRO. 2007. Nutrient Requirements of Domesticated Ruminants. M. Freer, H. Dove, and J. V. Nolan, ed. CSIRO Publishing, Collingwood, Australia.

Das, U. G., H. Jing, R. A. Ehrhardt, W. W. Hay Jr., and S. U. Devaskar. 2000. Time-dependent physiological regulation of ovine placental GLUT-3 glucose transporter protein. Am. J. Physiol. Regul. Integr. Comp. Physiol. 279:R2252-R2261.

Galgal, K. K., and M. K. Komolong. 2000. Copra meal and palm kernel supplementation with and without molasses and urea to weaner steers grazing Imperata cylindrica pastures in Papua New Guinea. Asian-australas. J. Anim. Sci. 13(B):261.

Grennan, E. J. 1999. Lamb growth rate on pasture: Effect of grazing management, sward type and supplementation. Sheep Series, No. 3. Teagasc Research Centre, Athenry, Co. Galway, Ireland.

Holmes, C. W., I. M. Brookes, D. J. Garrick, D. D. S. Mackenzie, T. J. Parkinson, and G. F. Wilson. 2002. Milk Production from Pasture. D. Swain, ed. Massey University, Palmerston North, New Zealand.

MacRae, J. C., J. S. Smith, P. J. S. Dewey, A. C. Brewer, D. S. Brown, and A. Walker. 1985. The efficiency of utilization of metabolisable energy and apparent absorption of amino acids in sheep given spring- and autumn-harvested dried grass. Br. J. Nutr. 54:197209

Mak, T. K., R. I. Hutagalung, and T. Togimin. 1986. Performance of Kedah-Kelantan cattle fed palm kernel cake. Pertanika J. Sci. Technol. 9:75-80.

Moorby, J. M., P. H. Robinson, W. J. Fisher, and R. T. Evans. 2008. Comparison of red clover and ryegrass silage for dry cows and influence on subsequent lactation performance. J. Dairy Sci. 91:3501-3511.

Muir, P. D., N. B. Smith, G. J. Wallace, G. J. Cruickshank, and D. R. Smith. 1998. The effect of short-term grain feeding on liveweight gain and beef quality. N. Z. J. Agric. Res. 41:517-526.

NRC. 2001. Nutrient Requirements of Dairy Cattle. 7th rev. ed. Natl. Acad. Sci., Washington, DC.

Nicol, A. M., and I. M. Brookes. 2007. The metabolisable energy requirements of grazing livestock. Pages 151-172 in Pasture and Supplements for Grazing Dairy Cattle. Vol. 14. P. V. Rattray, I. M. Brookes, and A. M. Nicol, ed. N. Z. Soc. Anim. Prod., Hamilton, New Zealand.

Roche, J. R., D. P. Berry, J. M. Lee, K. A. Macdonald, and R. C. Boston. 2007. Describing the body condition score change between successive calvings: A novel strategy generalizable to diverse cohorts. J. Dairy Sci. 90:4378-4396.

Roche, J. R., P. G. Dillon, C. R. Stockdale, L. H. Baumgard, and M. J. VanBaale. 2004. Relationships among international body condition scoring systems. J. Dairy Sci. 87:3076-3079.

Roche, J. R., N. C. Friggens, J. K. Kay, M. W. Fisher, K. J. Stafford, and D. P. Berry. 2009a. Invited review: Body condition score and 
its association with dairy cow productivity, health, and welfare. J. Dairy Sci. 92:5769-5801.

Roche, J. R., L. R. Turner, J. M. Lee, D. C. Edmeades, D. J. Donaghy, K. A. Macdonald, J. W. Penno, and D. P. Berry. 2009b. Weather, herbage quality and milk production in pastoral systems. 2 . Temporal patterns and intra-relationships in herbage quality and mineral concentration parameters. Anim. Prod. Sci. 49:200-210.

Russell, J. B., and C. J. Sniffen. 1984. Effect of carbon-4 and carbon-5 volatile fatty acids on growth of mixed rumen bacteria in vitro. J. Dairy Sci. 67:987-994.
Umunna, N. N., A. A. Yusuf, and A. A. Aganga. 1980. Evaluation of brewers' dried grains and palm kernel meal as major sources of nitrogen for growing cattle. Trop. Anim. Health Prod. 5:239-247.

VSN International. 2011. GenStat for Windows, UK. VSN International, Hemel Hempstead, UK.

Zahari, M. W., and A. R. Alimon. 2004. Use of palm kernel cake and oil palm by-products in compound feed. Palm Oil Dev. 40:5-9. 